\title{
National Nutrition Week 2021: Feeding Smart Right from Start-Role of Nursing Professionals
}

\author{
Subhash C Parija \\ Pondicherry Journal of Nursing (2021): 10.5005/jp-journals-10084-13116
}

The National Nutrition Week is observed every year from September 1 to $7 .^{1}$ The Food and Nutrition Board under the Ministry of Women and Child Development, Government of India makes intense efforts to propagate several aspects of human nutrition during the weeklong celebration. ${ }^{2}$ The nutrition week that is observed nationally is essentially aimed at creating robust awareness about better health and well-being. The nutrition week also focuses on mass education enabled through the National Nutrition Week campaign. During the nutrition week, various facets of food and balanced diet are discussed at length to make the people comprehend the importance of nutrition in a holistic and objectivized manner. ${ }^{3}$

The National Nutrition Week has a cherished history. This campaign was initiated by the Central Government in the year 1982 to basically foster good health and a balanced lifestyle facilitated through nutrition education. ${ }^{4}$ The effort assumes all the more relevance because malnutrition continues to be a global burden and the burden is pronouncedly threatening in the developing countries including India.

The theme for the National Nutrition Week 2021 is Feeding smart right from start. The theme centers around promoting healthy eating habits since the time of childbirth. This would go a long way in reducing the chances of illness, decreasing lifestylemediated disorders, and most significantly promoting better health right from the young age.

Having said that, it must be emphasized that over 40 units of the Food and Nutrition Board in our country are sincerely striving to develop working strategies based on process research for effective implementation and further planning. As per the 2020 Global Hunger Index, ${ }^{5}$ India ranks 94 th out of 107 countries. An alarming 14\% of the population in India is undernourished thus paving way for a plethora of nutritional diseases and disorders. This automatically calls for strict strategies and need-based implementation of the healthcare setup, NGOs, philanthropic establishments, and governmental organizations, all oriented toward eliminating undernutrition and malnutrition.

The role of nursing professionals in this regard is monumental. Nutrition continues to be an essential forte of nursing practice, as per the American Nurses Association (ANA). ${ }^{6}$ Nutrition is implicated in a patient's ability to respond to illness or injury, as per the American Association of Critical-Care Nurses (AACN). ${ }^{7}$ As regards nutrition education, nurses need to educate the patients during the stay in the hospital and also during the period of convalescence. This would enable quick recovery. Nutrition and Food safety play a crucial role in nursing education and public health nursing, in particular, according to the Indian Nursing Council. ${ }^{8}$ The
Vice-Chancellor, Sri Balaji Vidyapeeth (Deemed to be University), Puducherry, India

Corresponding Author: Subhash C Parija, Vice-Chancellor, Sri Balaji Vidyapeeth (Deemed to be University), Puducherry, India, Phone: +91 413-2616766, e-mail:vc@ sbvu.ac.in

How to cite this article: Parija SC. National Nutrition Week 2021: Feeding Smart Right from Start-Role of Nursing Professionals. Pon J Nurs 2021;14(3):51-52.

Source of support: Nil

Conflict of interest: None

Indian Nursing Council is a strong votary of nutrition education, as it is being implemented across the UG and PG programs throughout the country.

Midwives play a crucial role in women's health and nutrition. ${ }^{9}$ However, the fact remains that the midwives need assistance, valuable support, and guidance in order to impart holistic nutrition advice for achieving healthy pregnancies and desired outcomes. In the light of these facts, a cohesive approach involving midwifery bodies, nutritionists, dieticians, and education experts needs to be promulgated. ${ }^{10}$ Dedicated and committed comprehensive maternity care services that include all of the aforementioned services might provide the panacea that we are looking for.

In conclusion, it must be emphasized that a multidisciplinary approach needs to be envisaged in constituting nutritional support teams. ${ }^{11}$ The all-inclusive support teams should essentially comprise a physician, dietician, nutritionist, pharmacist, and nurse. The nurse in the multidisciplinary team is akin to one who is adept at advanced nursing practice. ${ }^{12}$ The nurse in such teams must possess sufficient knowledge, attitude, and professional competence expected of a nutritional expert in the specialized field of clinical nutrition.

Let the nurses care for the nutrition of the patients and let the nursing professionals imbibe the vital aspects of clinical nutrition in order to foster good professional practice.

\section{References}

1. Available from: https://pib.gov.in/newsite/PrintRelease. aspx?relid=170406.

2. Available from: https://wcd.nic.in/sites/default/files/WCD_AR_ English\%20final_.pdf.

3. Available from: https://www.healthcareradius.in/features/ wellness/30820-national-nutrition-week-2021-the-vital-role-ofnutrition-in-human-development.

4. Available from: https://main.mohfw.gov.in/sites/default/files/ Annual\%20Report\%202020-21\%20English.pdf.

(c) The Author(s). 2021 Open Access This article is distributed under the terms of the Creative Commons Attribution 4.0 International License (https://creativecommons. org/licenses/by-nc/4.0/), which permits unrestricted use, distribution, and non-commercial reproduction in any medium, provided you give appropriate credit to the original author(s) and the source, provide a link to the Creative Commons license, and indicate if changes were made. The Creative Commons Public Domain Dedication waiver (http://creativecommons.org/publicdomain/zero/1.0/) applies to the data made available in this article, unless otherwise stated. 
5. Pereira A, Handa S, Holmqvist G. Estimating the prevalence of food insecurity of households with children under 15 years, across the globe. Glob Food Sec 2021;28:100482. DOI: 10.1016/j.gfs.2020.100482.

6. Boeykens K, Van Hecke A. Advanced practice nursing: Nutrition Nurse Specialist role and function. Clin Nutr ESPEN 2018;26(3):72-76. DOI: 10.1016/j.cInesp.2018.04.011.

7. Gargasz A. Neonatal and pediatric parenteral nutrition. AACN Adv Crit Care 2012;23(4):451-464;quiz 465-466. DOI: 10.1097/ $\mathrm{NCl} .0 \mathrm{~b} 013 \mathrm{e} 31826 \mathrm{e} 8 \mathrm{f} 8 \mathrm{~b}$.

8. Available from: https://www.indiannursingcouncil.org/uploads/pdf/ 16179447312061820317606fe09b878f9.pdf.
9. Arrish J, Yeatman H, Williamson M. Self-reported nutrition education received by Australian midwives before and after registration. J Pregnancy 2017;2017:5289592. DOI: 10.1155/2017/5289592.

10. Arrish J, Yeatman $\mathrm{H}$, Williamson M. Australian midwives and provision of nutrition education during pregnancy: a cross sectional survey of nutrition knowledge, attitudes, and confidence. Women Birth 2016;29(5):455-464. DOI: 10.1016/j.wombi.2016.03.001.

11. Available from: http://cscc.scu.edu/trends/v21/v21_3.pdf.

12. Walker DK, Polancich S. Doctor of nursing practice: the role of the advanced practice nurse. Semin Oncol Nurs 2015;31(4):263-272. DOI: 10.1016/j.soncn.2015.08.002. 